\title{
Los golpes de Estado constitucionales en Latinoamérica: una amenaza emergente para el principio democrático
}

\section{Taking power by force in Latin America: an emerging threat to the democratic principle}

\author{
OMAR HUERTAS DÍAZ
}

Abogado, Ph.D® en Derecho, Especialista en Derecho Penal y Maestría en Educación; Máster en Derechos Humanos, Estado de Derecho y Democracia en Iberoamérica. Maestría en Derecho Penal; Ph.D@ en Ciencias de la Educación.

Profesor Asociado, Facultad de Derecho, Ciencias Políticas y Sociales Universidad Nacional de Colombia; ohuertasd@unal.edu.co

\section{VÍCTOR MANUEL CÁCERES TOVAR}

Becario de tiempo completo y exclusivo COLCIENCIAS-UN 2014 para cursar Doctorado en Derecho en la Universidad Nacional de Colombia; Máster en Derechos Humanos, Estado de Derecho y Democracia; Magister en Derecho Penal; Especialista en Derecho Internacional Humanitario y Derechos Humanos de la Universidad

Externado de Colombia.

vmcacerest@unal.edu.co

Para citar este artículo

Huertas, O., \& Cáceres, V (2014). Los golpes de Estado constitucionales en Latinoamérica: una amenaza emergente para el principio democrático. Justicia Juris, 10(2), 28-35.

Recibido: Julio 5 de 2014

Aceptado: Septiembre 25 de 2014

\section{RESUMEN}

El presente artículo de reflexión académica se enmarca en el campo de las Ciencias Jurídicas y es producto de los resultados de investigación sobre la interrelación existente entre los conceptos de Derecho Penal, Constitución y Derechos Fundamentales que los autores han venido adelantando desde una perspectiva analítica y crítica en el Grupo de Investigación Escuela de Derecho Penal "Nullum Crimen Sine Lege de la Universidad Nacional de Colombia -El artículo se refiere a los conflictos inter-orgánicos sucedidos en el actual siglo XXI en Honduras, Paraguay y Colombia y que a la postre llevaron a la salida del poder respectivamente de los presidentes Manuel Zelaya y Fernando Lugo y del Alcalde de Bogotá Gustavo Petro, todo dentro de un presunto marco de legalidad constitucional, destituciones que en el trasfondo fueron generadas por la configuración de los elementos de una innovadora y cada vez más usada tipología de derrocamiento del poder político por parte de los grupos antidemocráticos de los Gobiernos del hemisferio, cual es el denominado Golpe de Estado Constitucional, contexto emergente caracterizado ya no por el uso del accionar armado, sino por la toma y/o perpetuación del poder mediante la manipulación de las instituciones consagradas en la Carta superior.

Palabras Clave: Conflictos Inter-orgánicos, Democracia, Golpes de Estado Constitucionales, Latinoamérica, Orden Constitucional, Poder Político. 


\begin{abstract}
This article is part of an academic reflection in the field of Legal Studies. This is the product of the results of research on the interrelationship between the concepts of Criminal Law, Constitution and Fundamental Rights. The authors have been developing from an analytical and critical perspective Research Group in the School of Criminal Law "Crimen Sine Lege Nullum" National University of Colombia. This article is about the conflicts occurred in this century in Honduras, Paraguay and Colombia. This has ultimately led to ouster of presidents Manuel Zelaya, Fernando Lugo and the Mayor of Bogota Gustavo Petro. All the above, they took power presumably under constitutional law. Moreover, dismissals in the background were generated by the configuration of innovative and increasingly undemocratic groups of governments in the hemisphere. This is characterized not by the use of armed actions, but by making and / or perpetuation of power by manipulating institutions enshrined in the superior Charter.

Keywords: Inter-organic conflicts, Democracy, Constitutional, Latin-American, Constitutional Order, Political Power.
\end{abstract}

\section{Introducción}

El allanamiento en junio de 2009 de la residencia presidencial de Manuel Zelaya en Honduras y su posterior deportación ilegal a Costa Rica, la realización del juicio político express realizado en junio de 2012 al gobernante paraguayo Fernando Lugo que acarreó a la postre su salida del mandato, o la destitución en el año 2013 del Alcalde Mayor de Bogotá Gustavo Petro a instancias de la Procuraduría General de la Nación, son por citar algunos importantes ejemplos de recientes tomas o relevos de poder acaecidos presuntamente en el marco de una legalidad constitucional absoluta pero forjados como señala Marquardt (2011) por profundos conflictos inter-orgánicos latinoamericanos, que han generado en su fondo una innovadora y cada vez más usada tipología de toma del poder, cual es el denominado Golpe de Estado Constitucional, caracterizado en palabras del intelectual guatemalteco Mario Fuentes Destarac (2011), como la toma del poder político desde el mismo Gobierno constituido.

Y es precisamente por la reiterada práctica en los países de las Américas de esta nueva forma de Golpe de Estado como lo interpreta De Andrés (2000), que se pretende desde una perspectiva constitucional relacionar sus características y finalidades con los diferentes conflictos interorgánicos de orden político y jurídico desarrollados en la zona en tiempos recientes, todo bajo la pregunta ¿Los grupos antidemocráticos de los Gobiernos latinoamericanos han hecho toma del poder político con fines de concentración o perpetuación manipulando a su favor el orden legítimo constitucional bajo una apariencia de presunta legalidad?

La metodología empleada está basada en la propuesta presentada por Carvajal (2005) intitulada Investigación Social Aplicada relacionada con el estudio de fenómenos sociales y políticos, que para el caso serían los conflictos inter-orgánicos latinoamericanos seleccionados, mismos que están ligados con la legitimidad o no de las normas y/o decisiones proferidas a raíz de los trances políticos acaecidos en un contexto de poder. Se justifica igualmente el estudio propuesto toda vez que como señala Paramillo (2001), resulta de gran importancia para el constitucionalismo contemporáneo el reflexionar y profundizar sobre el concepto de Golpe de Estado Constitucional, fenómeno que se ve en su mayor proporción en los Estados latinoamericanos y que se genera fruto de conflictos interorgánicos jurídicos y sociales que no pueden ser ajenos al Derecho.

Para cumplir el objetivo cardinal propuesto, estructuralmente el presente documento se compone de tres (03) acápites: El primero de ellos analiza el concepto general de Golpe de Estado aterrizándolo en la caracterización fundamental del Golpe de Estado Constitucional; el segundo acápite, eje central del presente escrito, presenta y reseña brevemente tres de los principales conflictos interorgánicos sufridos por las democracias latinoamericanas y que han dado pie al surgimiento de Golpes de Estados constitucionales ya caracterizados, cuales son los de Honduras, Paraguay y el de la ciudad de Bogotá; finalmente, en el tercer y último punto, se reflexiona sobre cómo los conflictos inter-orgánicos que pueden generar en los Estados latinoamericanos la idea de Golpes de Estados Constitucionales, afectan el concepto de constitucionalismo moderno y el principio democrático ampliamente proclamado en las Américas. En forma de cierre, se presenta un breve cuerpo de conclusiones donde quedaran planteados algunos desafíos y reflexiones que servirán como punto de partida para una mejor aproximación y difusión de los contenidos elementales del constitucionalismo que debe operar en las democracias latinoamericanas.

Finalmente, y para un mejor entendimiento sistémico del documento que se ostenta, se considera pertinente e 
importante señalar que para la elaboración del presente escrito se han tomado en cuenta solo los conflictos interorgánicos sucedidos recientemente en Honduras, Paraguay y Colombia, obedeciendo a un criterio personal de selección que no excluye el valor jurídico, histórico y académico de aquellos que han sido omitidos.

\section{Aproximaciones al concepto de Golpe de Estado Constitucional}

El Golpe de Estado -del francés Coup d'État- tradicionalmente y en términos generales como lo refiere Sarmiento (2014), puede entenderse como la toma, o intento fallido de toma, del poder político de un modo repentino y violento por parte de un grupo de poder vulnerando, o intentado vulnerar, la legitimidad institucional establecida en un Estado. En relación con las acciones que conllevan los Golpes de Estados, el tratadista Carlos Sarmiento Sosa (1962) citando a Samuel E. Finer, distinguió varias acciones que se considerarían como tales:

1. Presión sobre el gobierno o los parlamentarios para influir a favor de los intereses de los golpistas;

2. Ultimátum a los Poderes Ejecutivo o Legislativo bajo advertencia de que, de no ser aceptadas las exigencias, se iniciarán otras acciones que equivaldrían a un "golpe de Estado tácito", obligando al gobernante a acatar las decisiones del grupo de presión.

3. Uso de la violencia o amenaza de violencia para reemplazar al gobierno civil por un gobierno civil o un gobierno militar.

Desde una perspectiva similar, el especialista Jesús De Andrés (2000) señala que un Golpe de Estado consiste en la alteración o destrucción del orden político por parte de las élites o de determinados cuerpos de la Administración, generalmente las fuerzas armadas; con el fin de conquistar el poder, controlarlo para permanecer en él, dirimir rivalidades o alejar y excluir a determinados grupos; recurriendo, tras una fase conspirativa y secreta, a la violencia o a la amenaza de su utilización; y suponiendo una ruptura de la legalidad que implica, en caso de éxito, cambios en las personas, políticas o normativa legal o, en caso de fracaso, modificaciones de diverso calado en el ritmo político (De Andrés, 2006).

En latinoamérica, refiere Cameron (1998), los Golpes de Estado durante la segunda mitad del siglo XX se caracterizaron por ser casi en su totalidad de carácter castrense, implantándose de esta forma, según Roitman (2013), rígidas dictaduras militares. Al respecto, en cita de Borón (2010), podemos citar sucesos golpistas tan representativos como el de Cuba por Fulgencio Batista en 1952; Rojas Pinilla en Colombia en el 1953; el derrocamiento de Jaco- bo Arbenz en Guatemala en 1954; la invasión armada promovida contra la Revolución Cubana en Playa Girón en 1961; el golpe de Estado contra Velazco Ibarra en Ecuador en 1961; el perpetrado en Brasil contra el presidente Joao Goulart en 1964; la invasión a República Dominicana el 28 de abril de 1965; el envío a Guatemala y Bolivia de asesores militares Boinas Verdes durante los años 1966 y 1967; los golpes de Estado en Uruguay y Chile en 1973; la Dictadura Militar en Argentina a partir de 1976; la intervención en el conflicto en El Salvador en 1980; el estímulo desde Honduras de la Guerra Sucia contra la Revolución Sandinista a partir de 1980; la invasión de Granada en 1983; la invasión de Panamá en 1989; entre otros muchos más.

Pero ya en el siglo XXI y ante el fortalecimiento teórico del discurso internacional de los Derechos Humanos, de los principios Derecho Internacional Público e interamericano y del concepto de Estado Constitucional de Derecho que entre otros trabaja Pérez (2005), los Golpes de Estado han sufrido una transformación que ha llevado a sus perpetradores a buscar el poder alejándose de las armas para emplear cada vez más el poder constituido (Borón, 2010). En otras palabras, según Roitman (2013), los golpes de Estado se han reestructurado en el siglo XXI, presentando otra cara, más "amable", sin tanta parafernalia militar, donde los grupos de poder de los Gobiernos se están aprovechando de las normas constitucionales para destruir la democracia desde adentro y así afianzar y perpetuar su poder bajo una apariencia de juridicidad, enfrentamos en la actualidad a los denominados Golpes de Estado Constitucionales.

El citado intelectual guatemalteco Fuentes Destarac (2011) amplía su concepto refiriendo que el Golpe de Estado Constitucional además de la toma del poder político desde el mismo Gobierno constituido, conlleva fines de concentración de poder (absolutismo y abuso), suplantación (ocupar o desempeñar ilegítimamente un cargo o función), desinstitucionalización (erosión o debilitamiento institucional), perpetuación (permanencia en el poder indefinidamente) y fraude electoral (defraudación de la voluntad popular), bajo una apariencia de legalidad.

Puede afirmarse que dicha categoría de situaciones golpistas se generan en su mayoría en conflictos interorgánicos sufridos al interior de cada una de las sociedades políticas afectadas, toda vez que en las mismas se presentan situaciones contrarias al orden constitucional contemporáneo, mismas que Fuentes (2011) ha enlistado como: 1)- La negación de los derechos fundamentales de los habitantes; 2)- La subordinación al Ejecutivo de los Organismos Legislativo, Electoral y Judicial, así como de las contralorías de cuentas; 3)- El irrespeto a la voluntad popular expresada en las urnas electorales; 4)- La poli- 
tización de las fuerzas armadas; 5)- La represión de la oposición política; 6)- La criminalización de la disidencia y la prensa independiente; y 7)- El histrionismo y la propaganda del odio.

Comentando esta vez la opinión del investigador colombiano Jorge Andrés Hernández (2013), esta clase o categoría de golpes de Estado pueden ser originados por conflictos inter-orgánicos de distinto orden al interior de los Estados, materializándose en acciones u hechos presuntamente legales pero que resultan adversos a los espacios democráticos y constitucionales para los ordenamientos jurídicos internos e incluso para los supra nacionales.

\section{Conflictos inter-orgánicos en América Latina como generadores de Golpes de Estado Constitucionales}

\subsection{Caso Manuel Zelaya en Honduras (2009)}

Relata Romero (2009) que en muy tempranas horas del 28 de junio de 2009, autorizadas por orden judicial de capturar a José Manuel Zelaya Rosales Presidente constitucional de la República de Honduras, debido a la supuesta comisión de delitos graves, como traición a la Patria y otros, las fuerzas armadas de la nación centro americana asaltaron el palacio presidencial y detuvieron al alto mandatario.

Posterior a su detención y en presunta violación de la Constitución de Honduras, señalan Booth \& Forero (2009) que los militares obligaron a abordar al presidente un vuelo hacia Costa Rica, y con Zelaya ya exiliado involuntariamente, el Congreso hondureño se reunió esa tarde, escuchó la lectura de una supuesta carta de renuncia de él, y la aceptó de inmediato. Relatan los mismos investigadores que acto seguido el Congreso emitió un decreto que pretendía destituir a Zelaya por otros motivos, y sustituirle por el presidente del Congreso, Rigoberto Micheletti. Así las cosas, se puede interpretar de lo ostentado por Booth \& Forero (2009), que el derrocamiento de Zelaya se produjo en un marco de presunta legalidad constitucional toda vez que fue dispuesto por órdenes de la Suprema Corte de Justicia de Honduras.

Resulta claro igualmente comentar que la detención y deportación de Zelaya se produjo fruto de un profundo conflicto inter-orgánico al interior de la sociedad hondureña, principalmente como consecuencia de la crisis política entre los máximos poderes públicos de la República que enfrentaba a Zelaya con el Congreso Nacional, el Tribunal Supremo Electoral y la Corte Suprema de Justicia, sobre la legalidad de una Cuarta Urna, para votar un referén- dum y cambiar así la constitución con presuntas miras reeleccionistas, por medio de una Asamblea Constituyente.

Adicionalmente, reafirma lo dicho señalar que en el caso hondureño se configuraron varios elementos para aseverar que estamos ante un caso de Golpe de Estado Constitucional, toda vez que grupos de poder por intermedio de la manipulación del orden constitucional, efectivamente se hicieron del mismo en un marco de presunta legalidad. El primero de los elementos enunciados resulta ser la expatriación forzosa del Presidente Zelaya, acción cuya constitucionalidad al parecer no fue examinada.

El segundo elemento fue la aceptación inmediata por el Congreso de la supuesta carta de "renuncia" - cuando era notorio que, horas antes, el supuesto autor había sido exiliado por la fuerza a Costa Rica. En tercer lugar está la falta evidente de competencia constitucional del Congreso para destituir a Zelaya en las circunstancias descritas. Un cuarto defecto en la destitución del presidente en cuestión es la falta del debido proceso legal, toda vez que conforme a la Convención Americana sobre Derechos Humanos, de la cual Honduras es Estado Parte toda vez que ratificó el instrumento internacional el 5 de septiembre de 1977, y que según el artículo 16 y 18 de la Constitución del país centroamericano prevalece por encima de la ley interna, los altos oficiales tienen derecho al debido proceso legal, antes de ser destituidos de sus cargos. Así las cosas, no sólo gozaba el Presidente Zelaya de tal derecho fundamental, por motivo de justicia hacia él, sino que quienes le eligieron tenían el derecho de no sufrir la anulación de su victoria electoral, sin proceso razonable para su destitución.

Es de interpretar que el caso hondureño se observa como el Congreso de aquel país motivado por un amplio conflicto inter-orgánico de conservación y obtención de poderes públicos, optó por no esperar el resultado del único remedio constitucional cual era un proceso penal ante la Corte Suprema de Justicia para destituir al electo presidente de turno, derrocando de este modo al mandatario de manera sumaria y arbitraria, configurándose de esta forma un claro ejemplo de un Golpe de Estado Constitucional que atentó contra los tratados internacionales y el principio democrático del país centro-americano y de la región en general.

\subsection{Caso Fernando Lugo en Paraguay (2012)}

Afirma De Cicco (2014) que la Crisis política en Paraguay de 2012 se desató a raíz de la moción de censura contra el entonces presidente de turno Fernando Lugo por la Cámara de Diputados de Paraguay, órgano parlamentario que acusó al gobernante electo en el 2008 por mal des- 
empeño de funciones, acusándolo -entre otras cosas- de responsabilidad política por los enfrentamientos entre campesinos y policías ocurridos días antes en Curuguaty, departamento de Canindeyú, con un saldo de diecisiete muertos, sucesos que posteriormente condujeron a la destitución de Lugo de su cargo por decisión parlamentaria.

En relación especifica al juicio político adelantado a Fernando Lugo, señala Colmán (2014) que este fue iniciado el miércoles 20 de junio de 2012 por el diputado opositor Luis Gneiting, quien presentó una propuesta de someter a juicio al presidente de la República por la responsabilidad política respecto a los mencionados sucesos de $\mathrm{Cu}$ ruguaty, misma que fue finalmente aprobada por amplio número de senadores. Afirma el mismo investigador que el escrito acusatorio presentado al Senado sostenía que el mandatario había gobernado de manera «impropia, negligente e irresponsable», generando «la constante confrontación y lucha de clases sociales, que como resultado final trajo la masacre entre compatriotas, hecho inédito en los anales de la historia desde nuestra independencia nacional hasta la fecha, en tiempo de paz».

Finalmente, la tarde del viernes 22 de junio de 2012, tan solo 48 horas después del inicio de la actuación procesal sancionatoria, tras constituirse en tribunal del juicio, el Senado paraguayo, presidido por Jorge Oviedo Matto, declaró culpable por 39 votos contra 4 a Fernando Lugo de los cargos esgrimidos en el libelo acusatorio y, minutos después, se tomó posesión en su reemplazo al vicepresidente Federico Franco, del Partido Liberal Radical Auténtico (Colman, 2014).

Es de señalar al respecto que efectivamente en Paraguay se utilizó un mecanismo contemplado en la Constitución cual era la moción de censura, pero fue aplicado de tal manera que violó no solo el espíritu de la Carta suprema sino toda práctica constitucional del mundo democrático, toda vez que la defensa de Fernando Lugo recurrió incluso a acciones de inconstitucionalidad ante la Corte Suprema de Justicia, con el fin de frenar el juicio político, aduciendo que no se respetaron los mínimos trámites procesales, principalmente en lo que refiere a que el Congreso aprobó un reglamento para viabilizar y cerrar el proceso en menos de veinticuatro horas, por lo que los abogados de Lugo no tuvieron el tiempo necesario para preparar una defensa jurídica apropiada (Anónimo, 2012).

Sin lugar a duda, interpreta Moldiz (2012), el contexto social y político paraguayo del año 2012 marco un claro conflicto inter-orgánico entre el poder ejecutivo en cabeza del presidente Lugo y el parlamento, en representación de la Cámara de Diputados, apuro que arrojó como resultado un golpe de Estado en el que al aplicarse la teo- ría planteada, observamos que no intervino ni una sola unidad militar ni tampoco se escuchó algún disparo, pero que a la postre derribo del poder a la autoridad designada legítimamente para el efecto en una presunta defensa de la democracia y el Estado Constitucional de Derecho.

Concretamente el Golpe de Estado Constitucional fue experimentado en Paraguay cuando en el mencionado mes de junio de 2012 en nombre presuntamente de la democracia pero en clara y flagrante negación de los derechos fundamentales internacionalmente reconocidos de uno de sus habitantes que ostentaba un fuero de mayor protección y garantía cual era el de presidente, en menos de 48 horas diputados y senadores abrieron y cerraron un juicio político en el que el Fernando Lugo, el acusado, no tuvo tiempo ni para defenderse, trayendo como resultado la remoción de su mandato por medio de la acción positiva del poder constituido en un aparente y todavía debatible manto de legalidad y constitucionalidad. De ahí que Moldiz (2012) haya dilucidado que la remoción del poder de Lugo fuera calificada internamente como "Golpe Parlamentario Express".

\subsection{Caso Gustavo Petro en Bogotá, Colombia (2013)}

El 30 de octubre de 2011, Gustavo Petro Urrego fue elegido Alcalde Mayor de Bogotá, cargo que asumió el 1 de enero de 2012. No obstante, el 9 de diciembre de 2013, el Procurador General de la Nación, Alejandro Ordóñez, destituyó de su cargo e inhabilitó por 15 años al alcalde por haber incurrido presuntamente en tres faltas disciplinarias gravísimas a titulo de dolo en el proceso de recolección de basuras en la ciudad (Anónimo, 2013).

En relación con este polémico caso que aún acapara la atención de miles de bogotanos y de instancias judiciales nacionales e internacionales entre las que se incluye la Comisión Interamericana de Derechos Humanos de la Organización de Estados Americanos (OEA), se observa un profundo conflicto inter-orgánico al interior de la sociedad capitalina y colombiana, y que enfrenta por un lado, al Alcalde de la ciudad más grande de Colombia quien fue electo popularmente, frente al mayor ente disciplinario de origen y facultades constitucionales y legales, específicamente en el hecho de conocer, interpretar y aplicar correctamente las facultades normativas otorgadas al Procurador General cuando se está ante un servidor de elección democrática y soberana como lo es el Alcalde Petro.

En otras palabras, el conflicto interno colombiano gravita en saber si las mencionadas facultades normativas del Procurador resultan por decirlo de alguna forma, infinitas, a tal punto de estar autorizado para investigar y 
sancionar disciplinariamente a todos los funcionarios públicos no solo por actos de corrupción sino por fallas en el desempeño de su gestión, último aspecto que incluiría la capacidad no solo de amonestar o suspender al funcionario, sino también de destituirlo de su cargo, inclusive a los de elección popular como ya se dijo lo es el mentando Alcalde, desconociendo, argumentan algunas posiciones, el voto otorgado por el elector (Anónimo, 2014).

Hay que reconocer en todo caso, según enseña Bromberg (2013), que la destitución del Alcalde Petro y el amplio término de su inhabilidad tuvieron un impacto político, de igual forma como si la decisión hubiera sido absolutoria. El periodista colombiano Jorge Andrés Hernández (2013) opina al respecto que el fallo de destitución del alcalde mayor de Bogotá, es una expresión de lo que Otto Kirchheimer (2001) denominó justicia política, esto es, "el uso de procedimientos legales con fines políticos" o, en otras palabras, el uso de la ley para influenciar la lucha por el poder político. En términos del mismo periodista, en el caso de la capital de Colombia el asunto adquiere ribetes de golpe de Estado con manto de juridicidad: con el pretexto de sancionar una política pública, que ya demuestra una extralimitación en el poder disciplinario, un funcionario administrativo destituye y prescribe la muerte política a una autoridad pública que para él representa, como pocos en la vida política contemporánea, un desafío a la "unanimidad moral del pueblo colombiano" y al "sagrado derecho a la continuidad" (Hernández, 2013).

En el mismo sentido, Hernández (2013) igualmente afirma que el fallo en cuestión vulneró elementos esenciales del derecho moderno: el debido proceso, la doble instancia, el derecho a la defensa, la garantía de la imparcialidad del juez; pero también vulnera buena parte de los valores constitucionales: sanciona a una política pública que sería la más razonable en un Estado Social de Derecho que protege a los más débiles y se consagra al interés general, elimina el principio democrático del Estado, destroza el principio de pesos y contrapesos que funda el Estado de Derecho, arrebata al presidente de la República sus competencias constitucionales y se erige en un poder supra-constitucional.

Finalmente e interpretando ya al periodista cafetero, en el caso colombiano se ha consumado un Golpe de Estado de ribetes constitucionales en toda regla, toda vez que para preservar lo que se considera valores fundamentales y superiores de la nación, se ha sacrificado los valores constitucionales y políticos del Estado democrático de derecho que se basa en la sujeción a las normas que los humanos se dan a sí mismos, y a su norma más alta en términos kelsianos, cual es la Constitución Política.

\section{Los golpes de Estado Constitucionales y los principios democráticos latinoamericanos}

Los continuos Golpes de Estado Constitucionales que están afectando en tiempo recientes a las sociedades latinoamericanas según Roitman (2013), y que reflejan graves y profundos conflictos inter-orgánicos en los países del hemisferio, no han sido temática olvidada para las entidades creadas con el fin de conservar el orden democrático y social de la región, y es por lo mismo que el 11 de septiembre de 2001, la Asamblea General de la OEA adoptó, por unanimidad, la Carta Democrática Interamericana, documento que en su artículo 9o autoriza a la Asamblea General para suspender de participación a un Estado miembro "cuyo gobierno democráticamente constituido sea derrocado por la fuerza".

En el mismo sentido, afirma Cassel (2009), el artículo 20 autoriza la convocatoria de una sesión especial de la Asamblea General, siempre que

en un Estado Miembro se produzca una alteración del orden constitucional que afecte gravemente su orden democrático" y a la postre el artículo $21 \mathrm{del}$ mismo documento internacional, autoriza a la misma Asamblea para suspender a un Estado miembro de participar en la organización, si "se ha producido la ruptura del orden democrático.

Al respecto y en palabras del mismo Cassel (2009), la Carta Democrática se erige como una salvaguarda colectiva para las democracias interamericanas que se vean afectadas por Golpes de Estados Constitucionales fruto de conflictos inter-orgánicos como los descritos, toda vez que establece normas internacionales que obligan (inter alia) a todo Estado que cumpla en lo pertinente con su propia constitución. Cierra Cassel (2009) afirmado que en la medida que la democracia depende del constitucionalismo, tal incorporación del derecho nacional en el derecho internacional es inevitable.

Finalmente es de señalar en relación a lo debatido que la Corte Europea de Derechos Humanos en el caso Sunday Times vs. United Kingdom del año 1979, interpretó que para evaluar si un Estado cumple con sus compromisos internacionales, no tienen más remedio que tomar en cuenta si las autoridades nacionales han vulnerado su propia constitución. Tal tarea, según interpreta de nuevo Cassel (2009), debe llevarse a cabo con todo respeto para la experticia nacional, procurando no evitarla, a menos que los regímenes de facto gocen de carte blanche para fabricar su constitucionalidad. 


\section{Conclusiones}

Las revocatorias recientes de poder sufridas por los presidentes democráticamente electos Manuel Zelaya en Honduras y Fernando Lugo en Paraguay, así como del igualmente elegido Alcalde Gustavo Petro en Bogotá no obstante su provisional restitución, entre otras muchas más acaecidas en el hemisferio americano hay que analizarlas desde un nuevo contexto donde ya no prevalecen los disparos y los contingentes militares que caracterizaron los escenarios golpistas del siglo $\mathrm{XX}$, sino como dice Fuentes Destarac (2011), se dan ahora por el accionar de los grupos antidemocráticos de los Gobiernos latinoamericanos que han hecho toma o conservación del poder político con fines de concentración o perpetuación manipulando a su favor y antojo el orden legítimo constitucional bajo una apariencia de presunta legalidad.

Tanto en Honduras como en Paraguay fue el parlamento el que acusó a electos presidentes de ser ellos los que violaban la constitución nacional, procediendo a destituirlos en nombre de la "democracia". En Bogotá por su parte, fue un órgano de control el que argumentando en todo momento la salvaguarda irrestricta de la Carta superior, realizo control político en un marco de presunta legalidad con el fin de destituir al alcalde favorecido popularmente, desconociendo la elección y voluntad de los sufragantes e imponiéndole a la postre una inhabilidad desproporcionada, desechándose en un muy mal síntoma y bajo la misma facultad, las medidas cautelares otorgadas a favor del disciplinado por parte de la Comisión Interamericana de Derechos Humanos, acabando de tajo un importante respeto que el ampliamente sancionado Estado colombiano había cultivado frente a las decisiones y recomendaciones proferidas por los órganos encargados de proteger y salvaguardar los Derechos Humanos en las Américas.

Así las cosas, las democracias latinoamericanas se enfrentan en esta centuria a un viejo enemigo ya conocido por todos, pero que se presenta hoy en día con nuevas galas y reformados aires, cual es el Golpe de Estado pero ahora con ribetes constitucionales, frente al cual se debe procurar respetar en todo momento los criterios de las autoridades nacionales, pero no obstante, ante una brecha clara de debilidad constitucional e institucional con efectos anti-democráticos, es esencial y mas que necesario el llamado e intervención internacional.

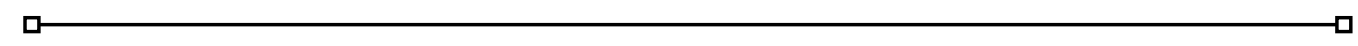

\section{Referencias}

\section{A. Textos}

Cameron, M. (1998). Presidential Coups d'État and Regime Change in Latin American and Soviet Successor States, Working Papers of The Kellogg Institute, 249.

Carvajal, A. (2005). Elementos de la Investigación Social Aplicada. Cartagena de Indias: Escuela Latinoamericana de Cooperación y Desarrollo.

De Andrés, J. (2000). Golpes de Estado a finales de siglo ¿el fin del golpismo?, El voto de las armas. Golpes de Estado en el sistema internacional a lo largo del siglo XX.

De Andrés, J. (2006). Golpe de Estado: Una Definición Tentativa. Madrid: UNED - Departamento de Ciencia Política.

De Andrés, J. (2000). Introducción, El voto de las armas. Golpes de Estado en el sistema internacional a lo largo del siglo XX.

Finer, S. (1962). The disposition to intervene (1) Motive, The Man on Horseback: The Role of the Military in Underdeveloped Countries.

González, E. (2004). Un Intento Preliminar de Definición y Caracterización del Golpe de Estado, Los golpes de Estado.

Kirchheimer, O. (2001). Justicia política. Empleo del Procedimiento Legal para Fines Políticos, trad. de R. Quijano. Granada: Comares.

Marquardt, B. (2011). La Era de la Estatalidad Anticonstitucional en Colombia (1949-1990), Revista Pensamiento Jurídico, 32.

Paramio, L. (2001). Tiempos del Golpismo Latinoamericano, Historia y Política (monográfico sobre golpes de Estado), 5.

Roitman, M. (2013). Tiempos de Oscuridad: Historia de los Golpes de Estado en América Latina. Santiago de Chile: Akal. 


\section{B. Documentos Electrónicos}

Anónimo, (2012). El Canciller de Ecuador sostiene que destitución de Fernando Lugo fue "un golpe de estado televisado". Recuperado el 02 de julio de 2012, de http://www.andes.info.ec/es/pol\%C3\%ADtica/3767.html

Anónimo, (2014). ¡ Ordóñez es Terminator! - Las descabezadas del procurador llegaron a un punto crítico. La destitución de Petro convirtió en mártir a un mal alcalde. Recuperado el 12 de junio de 2014, de http://m.semana.com/nacion/articulo/ destitucion-del-procurador-petro/368202-3

Anónimo, (2013). Procuraduría destituye e inhabilita por 15 años al alcalde de Bogotá, Gustavo Petro. Recuperado el 09 de diciembre de 2013, de http://www.elpais.com.co/elpais/colombia/noticias/procuraduria-destituye-petro-por-manejo-basuras-bogota

Borón, A. (2010). Invisibilizando Golpes de Estado: Lo que la Teoría Hegemónica en la Ciencia Política no quiere Ver. Recuperado el 05 de Enero de 2010, de http://redbetances.com/columnas/alejandro-torres-rivera/209--los-golpes-de-estado-enamerica-latina-los-peligros-que-enfrenta-venezuela.html

Bromberg, P. (2011). Ordóñez Vs. Petro: El Control sin Control y el Controlado Descontrolado. Recuperado el 16 de Diciembre de 2013, de http://razonpublica.com/index.php/politica-y-gobierno-temas-27/7254ordo\%EF\%BF\%BD\%EF\%BF\%BDez-vs-petro-el-control-sin-control-y-el-controlado-descontrolado.html

Cassel, D. (2009). Honduras: ¿Golpe de Estado en Vestido Constitucional? - Revisión. Recuperado el 15 de Octubre de 2011, de http://www.asil.org/insights/volume/13/issue/9/honduras-\%C2\%BFgolpe-de-estado-en-vestido-constitucionalrevisi\%C3\%B3n

Colmán, A. (2013). El día en que 39 senadores echaron un presidente. Recuperado el 21 de Junio de 2014, de http://www. ultimahora.com/el-dia-que-39-senadores-echaron-un-presidente-n628058.html

De Cicco, S. (2014). Corporatocratia: Los Verdaderos Dueños del Mundo. Recuperado el 1o de Febrero de 2014, de https:// medium.com/politica-y-sociedad/corporatocracia-973e8da84fa9

Fuentes, M. (2011). Golpe de Estado Constitucional. Recuperado el 03 de Enero de 2011, de http://elperiodico.com.gt/ es/20110103/opinion/187497

Hernández, J. (2013). ¿El Golpe de Estado de Ordóñez?. Recuperado el 13 de Diciembre de 2013, de http://www.razonpublica.com/index.php/politica-y-gobierno-temas-27/7263-\%C2\%BFel-golpe-de-estado-de ord\%C3\%B3\%C3\%B1ez. html

Fuentes, M. (2011). Golpe de Estado Constitucional. Recuperado el 03 de Enero de 2011, de http://elperiodico.com.gt/ es/20110103/opinion/187497

Moldiz, H. (2012). "Nuevos tipos" de golpe de estado y subversión permanente en América Latina. Recuperado el 26 de Junio de 2012, de http://www.cubadebate.cu/opinion/2012/06/26/nuevos-tipos-de-golpe-de-estado-y-subversion-permanente-en-america-latina/\#.U5nJDihG1o4

Romero, O. (2009). Golpe de Estado en Honduras. Manuel Zelaya capturado por los militares. Los intereses que entran en juego. Recuperado el 28 de Junio de 2009, de http://orhpositivo.wordpress.com/2009/06/28/golpe-de-estado-en-honduras-manuel-zelaya-capturado-por-los-militares/

Sarmiento, C. (2014). ¿Qué es un Golpe de Estado? Recuperado el 15 de Mayo de 2014, de http://www.eluniversal.com/ opinion/140515/que-es-un-golpe-de-estado 